This item was submitted to Loughborough's Research Repository by the author.

Items in Figshare are protected by copyright, with all rights reserved, unless otherwise indicated.

\title{
Simplified analytical assessment of damaged induced by the external sulphate attack in concrete piles
}

PLEASE CITE THE PUBLISHED VERSION

https://doi.org/10.1007/978-3-319-59471-2_260

\section{PUBLISHER}

(c) Springer International Publishing

\section{VERSION}

AM (Accepted Manuscript)

\section{PUBLISHER STATEMENT}

This work is made available according to the conditions of the Creative Commons Attribution-NonCommercialNoDerivatives 4.0 International (CC BY-NC-ND 4.0) licence. Full details of this licence are available at: https://creativecommons.org/licenses/by-nc-nd/4.0/

\section{LICENCE}

CC BY-NC-ND 4.0

\section{REPOSITORY RECORD}

Ikumi, Tai, Sergio H. Cavalaro, Ignacio Segura, Chris I. Goodier, and Simon A. Austin. 2019. "Simplified Analytical Assessment of Damaged Induced by the External Sulphate Attack in Concrete Piles". figshare. https://hdl.handle.net/2134/26576. 


\title{
Simplified analytical assessment of damaged induced by the external sulphate attack in concrete piles
}

\author{
Tai Ikumi ${ }^{1}$, Sergio Cavalaro ${ }^{1}$, Ignacio Segura ${ }^{2}$, Chris Goodier $^{3}$ and Simon Austin ${ }^{3}$ \\ ${ }^{1}$ Department of Civil and Environmental Engineering, Universitat Politècnica de \\ Catalunya, Barcelona Tech, Jordi Girona 1-3, C1, E-08034 Barcelona, Spain, email: \\ tai.ikumi@upc.edu, sergio.pialarissi@upc.edu \\ ${ }^{2}$ Smart Engineering Ltd., C/Jordi Girona 1-3, Parc UPC - K2M, 08034, Barcelona, Spain; \\ email: ignacio.segura@,upc.edu \\ ${ }^{3}$ School of Civil and Building Engineering, Loughborough University, Leicestershire, \\ LE11 3TU, U.K., email: C.I.Goodier@,lboro.ac.uk, S.A.Austin@lboro.ac.uk
}

\begin{abstract}
Underground structures and foundations, including piles, constructed with reinforced concrete may be in contact with sulphate-rich soils and water. Structural elements exposed to these conditions may be affected by an expansive process known as external sulphate attack (ESA) that generally leads to an increase in volume, hence displacements and cracking of the concrete. The most widely accepted approach to mitigate such problems is to use cement(s) with a small content of aluminates. The objective of this research was to assess the potential damage induced by ESA using a simplified analytical model that is able to consider parameters such as the cement content and size of the pile, which may also affect the risk of damage. A parametric study was performed with different pile sizes and aluminate and cement contents. The structural integrity of the elements was verified considering a life span of 50 years and three possible failure modes (tensile failure in the core, and shear or tensile failure in the interface between the damaged and undamaged regions). The results suggest that the recommendations based solely on the maximum aluminate content present in the cement are inaccurate and might lead to very different outcomes depending on the characteristics of the elements. The study indicates that other parameters should also be taken into account in order to reduce the risk of ESA in real structures, such as the size of the element or the cement content per unit volume of concrete. This work has implications for the design of pile foundations in ground conditions prone to sulphate attack.
\end{abstract}

Keynotes: Concrete; Durability; External sulphate attack; Diffusion; Failure 


\section{INTRODUCTION}

External sulphate attack (ESA) is a complex degradation process affected by multiple variables related to the transport process of sulphate ions, material reactivity and mechanical and geometrical properties of the element under attack (Skalny J.P., 2001, Neville A., 2004). Despite its complexity, most codes of practice assess this phenomenon by solely considering the severity of the exposure conditions (e.g. Model Code 2010, BS 8500-1:2006, ACI 201.2R-08, UNE EN 206-1:2008). Based on that, codes prescribe limits for maximum water/cement ratio, minimum cement content and compressive strength and recommendations on the type of cement. The reasoning behind these recommendations is to obtain a dense, workable concrete with low reactivity to sulphates able to withstand the internal stresses caused by the expansions.

The appropriate type of cement is selected on the basis of its chemical constituents, in particular the $\mathrm{C}_{3} \mathrm{~A}$ content. Therefore, according to the design codes it seems that the reactivity of the material is defined by the aluminate content in the cement. However, common sense suggests that it is the aluminate content per unit volume of concrete what determines the reactivity, which is strongly influenced by the cement content. Concrete with a high content of sulphate-resisting cement for example, could potentially concentrate more aluminate than concrete with a lower content of non sulphate-resisting cement. Therefore, an assessment based solely on the aluminate content in the cement might lead to imprecise outcomes that might compromise the security of the structure.

Due to the interaction of several chemical agents, many practitioners perceive the ESA as an entirely chemical attack. This view is supported by structural codes since most of the recommendations included are focussed on reducing the penetration of sulphates or the reactivity of the material. However, unlike internal degradation processes, the region directly affected by sulphate penetration is usually restricted to a few centimetres close to the external surface. The sound region, which in most real structures constitutes a larger area, contributes to reduce the damage caused by the attack due to equilibrium and compatibility with the damaged area. In this context, it seems inaccurate to classify ESA as an entirely chemical phenomenon. Despite structural codes must contain simplified approaches, ignore the mechanical contribution might lead to unnecessary penalizing measures in some situations.

This paper uses a simplified analytical model to evaluate the influence of cement content and the geometrical characteristics of the element on the stresses generated by ESA. The structural integrity of the elements is verified considering a life span of 50 years and three possible failure modes. A full parametric analysis is performed considering different sizes of piles (between 20 and $120 \mathrm{~cm}$ diameter) and cement contents (between 260 and 400 $\mathrm{kg} / \mathrm{m}^{3}$ ). The influence of diameter and cement content is assessed for cements with different aluminate contents. 


\section{SIMPLIFIED METHODOLOGY}

The methodology is based on the application of a set of simplified equations to assess the extent of the reactive-transport process and the possible mechanical structural failure at a given service life. Figure 1 depicts a schematic outline of the methodology for pile structures with a service life of 50 years. The assessment takes into account the severity of the exposure conditions, the reactivity of the material and the geometric characteristics of the element under attack. An in-depth description of the derivation process of the equations presented in Figure 1 is available in (Ikumi T., 2016).

\subsection{Simplified reactive-transport equations}

Eq. 1 describes the analytical expression to estimate the penetration of sulphate ions. To simplify the mathematical representation of the transport process, only the penetration of sulphate ions by a concentration gradient and its depletion due to ettringite formation is considered. It is assumed that the system is saturated and all pores are accessible. The initial diffusivity $\left(D_{0}\right)$ is introduced in $\mathrm{m}^{2} / \mathrm{s}$, whereas the aluminate content $\left(C_{C A}\right)$ is expressed in mol per cubic meter of concrete. The sulphate content $\left(C_{S O}\right)$ is expressed in mol of sulphate per cubic meter of water. As this equation is deduced from the model described by (Ikumi T., 2014), sulphate consumption, acceleration of the penetration due to cracking and decrease of diffusivity due to pore filling are indirectly considered.

Maximum expansions developed are estimated by Eq. 2. It is assumed that the expansion mechanism associated to the ESA is based on the additional volume generated by the ettringite formation (Tixier R., 2003). The increase of volume $(\Delta V / V)$ is calculated by the stoichiometric constant of the reaction. This calculation gives a 55\% volume increase when monosulphate is converted into ettringite (Clifton JR., 1994). The term $M / \rho$ corresponds

to the molar volume of monosulphate and $C_{C_{4} A \bar{S} H_{12}}$ refers to the amount of monosulphate reacted (expressed as a molar concentration). Maximum expansive strain is calculated by assuming that all monosulphate reacts to form ettringite. In the second term of Eq. 2, $\varphi_{0}$ corresponds to the initial porosity of the matrix and $f$ is the fraction of this porosity that may be filled by expansive products before expansions occur. To simplify the structural consideration, it is assumed that the whole penetrated region estimated by Eq. 1 is affected by the same expansions.

\subsection{Simplified mechanical equations}

Expansions developed at the micro-structural level estimated by Eqs. 1 and 2 are translated to the macro-scale by taking into account the mechanical properties and geometric characteristics of the element under attack. By this way, it is possible to consider the positive contribution of the sound fraction of the section and assess the most common failure modes associated to ESA. Although expansion due to ettringite formation is concentrated in the superficial layers, strains also appear in the sound core of the element 
to ensure compatibility. In fact, the sound core acts as a restriction that reduces the expansion calculated with Eq. 2. An auto-balanced tension state is generated, leading to possible mechanical failures outside the zone directly affected by the sulphate penetration.

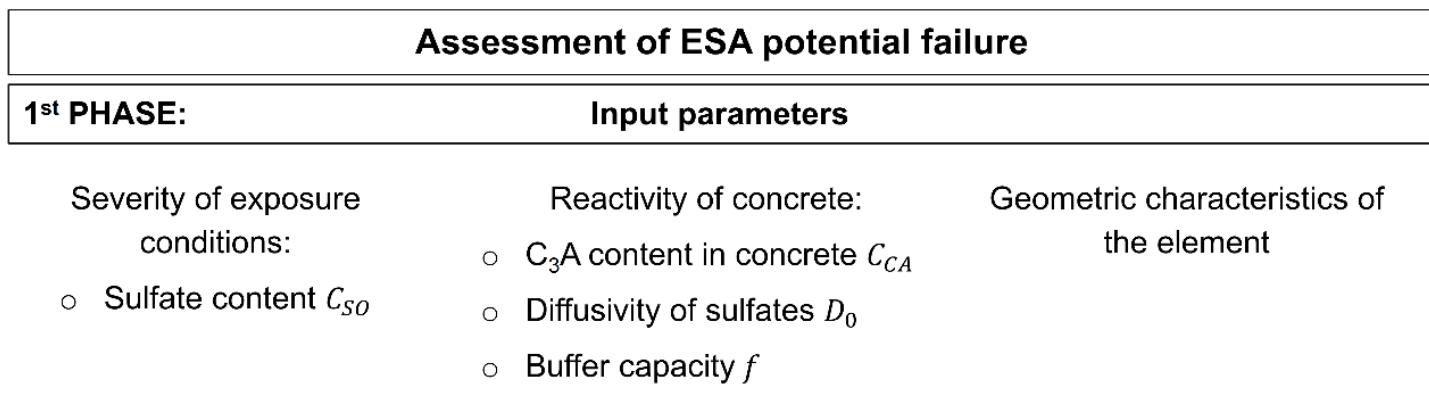

$2^{\text {nd }}$ PHASE: $\quad$ Simplified reactive-transport equations

○ Max. Penetration: $\quad P=1.26\left(7 e 10 D_{0}+0.035 C_{S O}\right) \exp \left(\frac{6.65 e 11 D_{0}+10.737}{C_{C A}}-\frac{1 e-10}{35 D_{o}} f\right)$

○ Max. Expansion: $\quad \varepsilon_{l}=\left(1+\frac{\Delta V}{V} \frac{M}{\rho} C_{C_{4} A \bar{S} H_{12}}^{T o t}-f \varphi_{0}\right)^{1 / 3}-1$

$3^{\text {th }}$ PHASE:

Simplified mechanical equations

- Tensile core failure

- Shear failure

Tensile boundary

$\sigma_{t c}=\frac{E_{0} E_{e} \varepsilon_{l}\left(R^{2}-R_{i}^{2}\right)}{E_{e}\left(R^{2}-R_{i}^{2}\right)+E_{0} R_{i}{ }^{2}}$ (Eq. 3) $\tau_{b}=\frac{E_{0} E_{e} \varepsilon_{l}\left(R^{2}-R_{i}^{2}\right) R_{i} \beta_{r}}{2\left(E_{e}\left(R^{2}-R_{i}^{2}\right)+E_{0} R_{i}{ }^{2}\right)} \tanh \left(\frac{\beta_{r} l}{2}\right)$ (Eq. 4) $\quad \begin{gathered}\text { failure } \\ \sigma_{t b}=\frac{\varepsilon_{l} E_{e} P}{R_{i}} \text { (Eq. 6) }\end{gathered}$
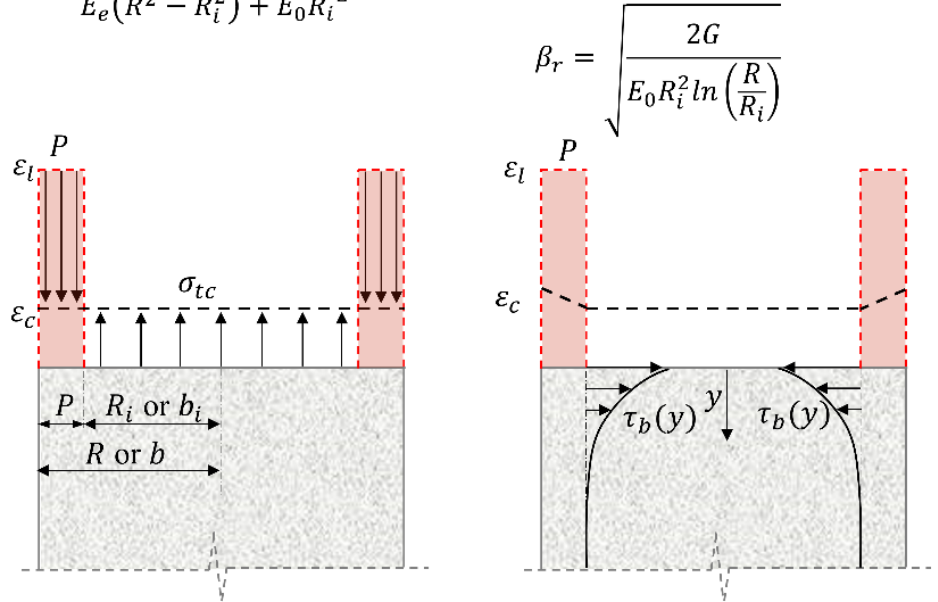

(Eq. 5)

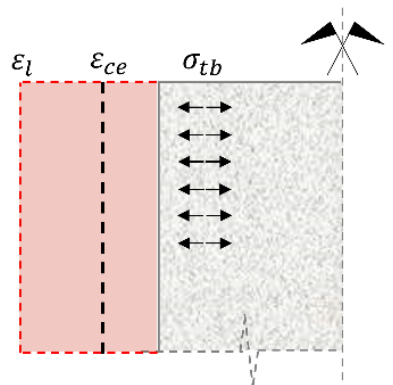

Figure 1. Outline of the simplified methodology for the ESA assessment.

Three failures modes are distinguished; tensile failure of the sound core, shear failure and tensile failure in the boundary between the surficial layers and the sound core. The compressive stresses generated in the external layers are not considered as a failure mode. However, these are considered indirectly in the simplified transport equations by a 
degradation of the elastic modulus in the affected region (Ikumi T., 2016). Figure 1 includes the final expressions for the assessment of the three failure modes in piles under symmetric exposure conditions (Eqs. 3-6) and the stress distribution for each case. If no mechanical failure occurs and the serviceability is not compromised, it is considered that the structure will comply with the required service life.

\section{SENSITIVITY ANALYSIS}

A total of 100 simulations were carried out to assess the influence of the cement content and pile diameter on the risk of mechanical failure associated to ESA for different $\mathrm{C}_{3} \mathrm{~A}$ contents. All combinations between parameters and values included in Table 1 are analysed.

Table 1. Range of parameters in the sensitivity analysis.

\begin{tabular}{ccc}
\hline $\begin{array}{c}\text { Cement content } \\
{\left[\mathrm{kg} / \mathrm{m}^{3}\right]}\end{array}$ & $\begin{array}{c}\text { Cement } \mathrm{C}_{3} \mathrm{~A} \\
{[\%]}\end{array}$ & $\begin{array}{c}\text { Pile diameter } \\
{[\mathrm{cm}]}\end{array}$ \\
\hline 260 & 5 & 20 \\
295 & 6 & 40 \\
330 & 7 & 80 \\
365 & 8 & 120 \\
400 & 9 & \\
\hline
\end{tabular}

The sulphate concentration was fixed at $3 \mathrm{~g} / \mathrm{l}$, which corresponds to a highly aggressive exposure class according to the European Standard EN 206-1. Initial diffusivity and the buffer capacity of the matrix are $10^{-12} \mathrm{~m}^{2} / \mathrm{s}$ and 0.10 , respectively. Possible alterations on the transport process caused by different cement contents are not taken into account. The length of the structural element is fixed at $5 \mathrm{~m}$, which is above the critical length for the assessment of the tangential stresses (Ikumi T., 2016). This means that the results derived from the parametric study also apply to larger elements. The compressive strength and the elastic modulus of concrete are fixed at $30 \mathrm{MPa}$ and $28000 \mathrm{MPa}$, respectively. The elastic modulus was considered the same at the sound core and at the superficial layers affected by ESA. This consideration is on the safe side since it provides higher internal stresses (Eqs. 3-6). The tensile strength of the material is approximated through the formulation included in the Model Code. The shear strength is set at 7.1 MPa based on the formulation proposed by (Kaneko Y., 2004).

Figure 2 shows the influence of cement content on the stresses developed for different aluminate contents and pile diameters. To ease the interpretation of the graphs, the different failure modes are represented as the ratio between the stress and its corresponding strength. Failure occurs when the ratio become bigger than 1 . As expected, an increase of the cement content resulted in an increase of the risk of failure for all $\mathrm{C}_{3} \mathrm{~A}$ contents considered. The stresses generated corresponding to the main failure mode (shear) in piles of $\varnothing 120 \mathrm{~cm}$ with $5 \% \mathrm{C}_{3} \mathrm{~A}$ increase from 0 to $12 \%$ of the shear strength of the material when the cement content increases from 260 to $400 \mathrm{~kg} / \mathrm{m}^{3}$. The influence of cement content becomes more 
significant in cements with high $\mathrm{C}_{3} \mathrm{~A}$ contents. In compositions with $\mathrm{C}_{3} \mathrm{~A}$ contents above $7.4 \%$, the shear stresses generated increase from values ranging between $10-43 \%$ of the shear strength of the material to failure.

Results for other pile sizes indicate that the influence of the cement content on the stress level also increases with the decrease of the diameter. The stresses developed in piles of $\varnothing 20 \mathrm{~cm}$ with a $5 \% \mathrm{C}_{3} \mathrm{~A}$ cement might vary from null to $55 \%$ of the strength of the material depending on the cement content selected. This large range of variation might lead to unexpected outcomes in some situations. Figure $2 \mathrm{~d}$ highlights the fact that elements using a sulphate-resisting cement might develop higher stresses than elements with non sulphateresisting cement if the cement content is not specified (shaded region).
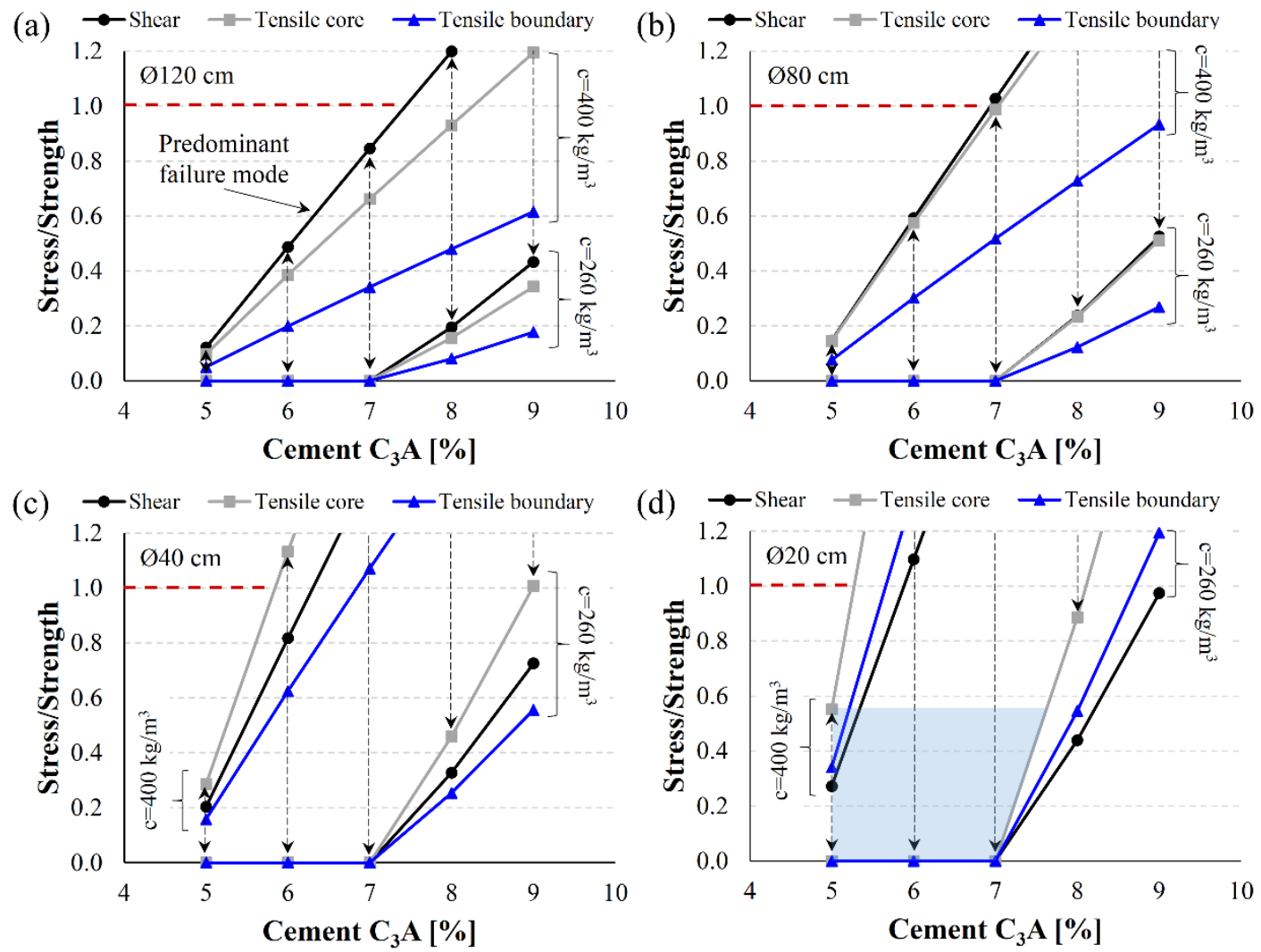

Figure 2. Stress/Strength ratios for different cement and $\mathrm{C}_{3} \mathrm{~A}$ contents in piles of (a) 120, (b) 80, (c) 40 and (d) $20 \mathrm{~cm}$ of diameter.

Figure 3 presents the influence of the cement content and size of the piles on the maximum $\mathrm{C}_{3} \mathrm{~A}$ content prior failure (referred to as $\mathrm{C}_{3} \mathrm{~A}$ Threshold) for the different failure modes considered. An increase of the cement content from 260 to $400 \mathrm{~kg} / \mathrm{m}^{3}$ causes a 33 to $35 \%$ reduction on the $\mathrm{C}_{3} \mathrm{~A}$ Threshold for all sizes and failure modes considered. On the other hand, increasing the pile diameter from 20 to $120 \mathrm{~cm}$ causes an increase of around $40 \%$ 
of the $\mathrm{C}_{3} \mathrm{~A}$ Threshold corresponding to the critical failure mode for all cement contents considered.

Interestingly, the predominant failure mode predicted also depends on the size of the element. Large diameters seem to promote the delamination of the external layers due to the shear stresses in the boundary of the sound and affected regions. On the other hand, for smaller diameters tensile failure in the core might be the critical failure mode. This could explain the low amount of ESA-related collapses in field conditions. Most of the structures exposed to ESA are large elements such as foundations, waste containers or tunnels, which might tolerate the spalling of the external layers without compromising the overall performance of the structure.
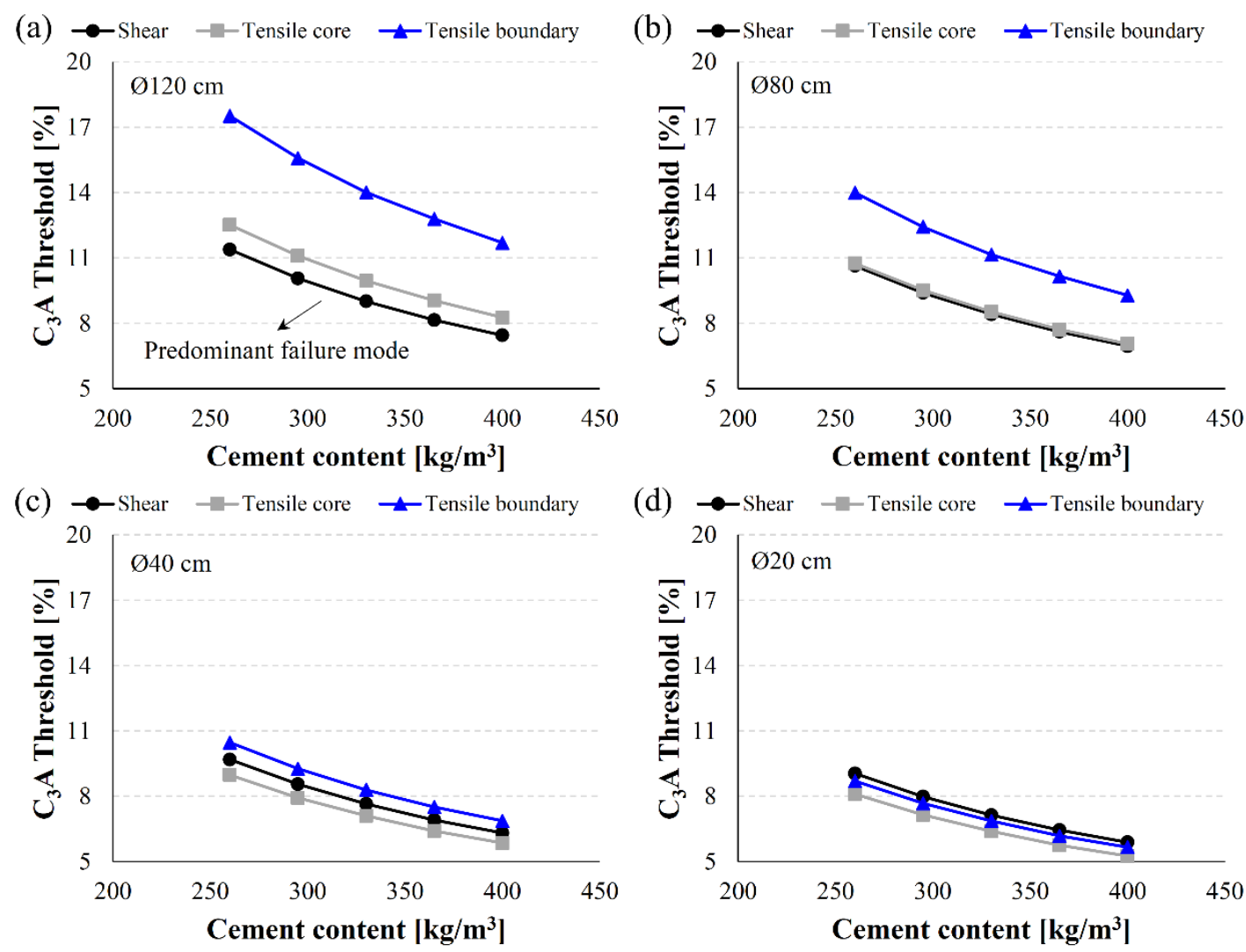

Figure 3. $\mathrm{C}_{3} \mathrm{~A}$ Threshold for different cement contents and failure modes in piles of (a) 120, (b) 80, (c) 40 and (d) $20 \mathrm{~cm}$ of diameter.

\section{CONCLUSION}

A direct and straightforward methodology is used to analyse the effects of cement content and size on the durability of piles exposed to ESA. The following conclusions may be derived from this study: 
- The limitation of the $\mathrm{C}_{3} \mathrm{~A}$ content in the cement included in most structural codes may lead to a wide variety of outcomes depending on the cement content considered.

- Results highlight the influence of the pile diameter on the assessment of the damage induced by ESA and the predominant failure mode expected. Results indicate that spalling of the external layers might be the main failure mode in large elements. However, for slender elements, tensile failure in the core might occur prior to delamination.

- Both the cement content and the size of the element should be considered in the assessment of the durability of piles exposed to ESA. The limitation of aluminate content included in the codes should be referred to as the $\mathrm{C}_{3} \mathrm{~A}$ content per unit volume of concrete.

\section{ACKNOWLEDGMENTS}

Support from the Spanish Ministry of Economy and Competitiveness through research project BIA2013-49106-C2-1-R is greatly acknowledged. T. Ikumi is supported by the fellowship program FPI of the Spanish Ministry of Economy and Competitiveness.

\section{REFERENCES}

Clifton, JR. and Pommersheim, JM. (1994). "Sulphate attack of cementitious materials: volumetric relations and expansions." Building and Fire Research Laboratory, National Institute of Standards and Technology.

Ikumi, T., Cavalaro, S.H.P., Segura, I. and Aguado, A. (2014). "Alternative methodology to consider damage and expansions in external sulphate attack modeling." Cem. Concr. Res. 63, 105-116.

Ikumi, T., Cavalaro, S.H.P., Segura, I., De la Fuente, A. and Aguado, A. (2016). "Simplified methodology to evaluate the external sulphate attack in concrete structures." Mat. Des. 89, 1147-1160.

Kaneko, Y., Mihashi, H. and Ishihara, S. (2004) "Shear failure of plain concrete in strain localized area." Proceeding of the Fifth International Conference on Fracture Mechanics of Concrete and Concrete Structures, Colorado, USA, V.C. Li, C.K.Y. Leung, K.J. Willam and S.L. Billington (ed.), 12-16 (1), 383-390.

Neville, A., (2004) "The confused world of sulfate attack on concrete." Cem. Concr. Res. 34, 1275-1296.

Skalny, J.P., Odler, I. and Marchand, J. (2001) "Sulfate Attack on Concrete", Spon, London.

Tixier, R. and Mobasher B. (2003) "Modeling of damage in cement-based materials subjected to external sulfate attack. I: formulation." J. Mater. Civ. Eng. 15, 305313. 